\title{
RESEARCH PAPER \\ A HIDDEN MARKOV MODEL-BASED APPROACH IN BRANDSWITCHING (A CASE STUDY OF THE NIGERIAN TELECOMMUNICATION SECTOR)
}

\author{
${ }^{1}$ F. Opone and ${ }^{2}$ N. Ekhosuehi \\ Department of Mathematics, University of Benin, Benin City, Nigeria \\ ${ }^{1}$ festus.opone@physci.uniben.edu \\ ${ }^{2}$ nosakhare.ekhosuehi@uniben.edu
}

\begin{abstract}
In this work, we considered a Hidden Markov Model for the Telecommunication Industry in Nigeria. There are five major mobile service providers presently in Nigeria: MTN, AIRTEL, GLOBACOM, ETISALAT and NITEL. We proposed a model for decision making in this sector by examining the rationale behind customers' brand switching. Our sample comprises of 512 respondents from a total population of 37,083 persons in the University of Benin, which consists of academic staff, non-academic staff and students; using proportional allocation to size in the stratified random sampling. As part of the decision making using the proposed model, we observed a set of marketing strategies and then applied our model to project the mobile service providers that stand a chance of relevance in the sector. Our result suggests that, if subscribers of different networks decide to switch from their current network based on these rationales [Price, Service Quality, Brand loyalty, Price and Trust] in a consecutive period of five years, the best marketing strategies for the mobile service provider [GLOBACOM] in the first three years are Price, Service Quality and Brand loyalty respectively. While the mobile service provider [MTN], should invest in the Pricing System and increase the level of Trust existing between them and their subscribers in the fourth and fifth year respectively.
\end{abstract}

Keywords: Hidden Markov Models; Brand switching; Telecommunication Sector

\section{INTRODUCTION}

The Nigerian Telecommunications Network has experienced a dramatic change in its development since the first mobile network was launched in the country in 2001. This sector is recorded as the biggest and fastest growing market in Africa and eighth in the world. This experience has brought a relatively high rate of competition among mobile service providers, causing them to seek for more profit making marketing strategies to keep their customers as well as influencing subscribers of other service providers to switch to their service. Such marketing strategies, emanate from the rationale 
behind customers' brand switching. In this paper, we use a Hidden Markov Model (HMM) to model the rationale behind customer's switching in the Telecommunication Sector.

The HMM has been applied to many areas. Examples can be found in Rabiner (1989), Juang and Rabiner (1991), Ezzaine (2006), Bhusari and Patil (2011) and a host of others. In this paper, we examine a HMM-Based approach in brand switching, considering the telecommunication sector in Nigeria as a casestudy.

\section{LITERATURE REVIEW}

Bickel et al.(1998), described a Hidden Markov model as a discrete-time stochastic process

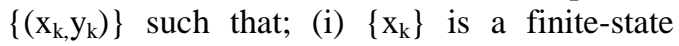
Markov chain, and (ii) given $\left\{x_{k}\right\},\left\{y_{k}\right\}$ is a sequence of conditionally independent random variable with the conditional distribution of $y_{n}$ depending on $\left\{\mathrm{x}_{\mathrm{k}}\right\}$ only through $\mathrm{x}_{\mathrm{n}}$. They suggests that the name Hidden Markov model is motivated by the assumption that $\left\{\mathrm{x}_{\mathrm{k}}\right\}$ is not observable, so that inference has to be based on $\left\{\mathrm{y}_{\mathrm{k}}\right\}$ alone.

Ghahramani (2001), stated that the understanding of HMM has changed considerably since the realization that they are a kind of Bayesian Networks and can be used to discuss general solution to the problem of approximate inference, parameter learning and model selection. A Bayesian network is a graphical model for representing conditional independencies between a set of random variables. He suggested that HMM falls in a subclass of Bayesian networks known as dynamic Bayesian network which are simply designed for modeling time series data. Here the assumption that an event can cause another event in the future, but not vice versa, simplifies the design of the Bayesian network.

Bhusari and Patil (2011), extended the application of Hidden Markov model in the area of credit card fraud detection. The system was used to analyze the spending profile of the card holder and followed by checking an incoming transaction against spending behavior of the card holder. If any variance is detected, then it would be considered a fraud transaction. The spending profile of the card holder is generated by the analysis of previous transaction data, as every credit card user has a unique pattern containing information about the amount of transaction, details of purchased goods, date of transaction and merchant information etc. The HMM-based system is trained to track fraud transaction through the internet, if any anomaly is noticed from the existing patterns of the credit card user, by generating an alarm to the system to stop the transaction.

Gautam and Chandhok (2011) investigated the determinants that influence mobile phone customers to switch from one service provider to another by examining what keeps a customer loyal as well as what provokes the same customer to switch. Their finding suggests that switching may be due to changes in the underlying determinants which includes; customer satisfaction, service quality, users' relational investments and user demographics. Much emphasis was laid on customer satisfaction as it follows that the more satisfied a customer is, the less he or she is prone to complain.

Sarwat et al. (2013) further suggests that the factors responsible for customers switching from one mobile service to another are basically, the Pricing system, Service Quality, Trust and Brand loyalty. Their work was based on examining these factors by setting an hypothesis using Statistical test of hypothesis based on regression and correlation analysis. Their result suggests that service quality does not influence customers to switch a network and that price and trust have positive impacts on brand switching while brand loyalty has a negative impact on brand switching.

\section{PROCEDURE AND METHODS}

Our procedure for this paper was based on considering the five major mobile service providers in Nigerian Telecommunication Sector includ- 
HMM-Based approach in brand switching...

ing MTN, AIRTEL, GLOBACOM, ETISALAT and NITEL. We critically examined the rationale for a subscriber of a particular network to switch to another network. This study was limited to a sample taken from the entire population of the University of Benin, Edo State, Nigeria. The sample taken includes the academic staff, non-academic staff and students who are subscribers of the different telecommunication networks in Nigeria. For a brief understanding of the procedure, we define the following useful concepts:

\section{Brand switching}

Brand switching is described as a process in which a customer switches from using a particular brand of product to another brand of the same kind. In real-life situation, it is commonly observed that customers switched from one brand to another brand based on some level of dissatisfaction, and the telecommunication sector is not excluded from this assertion. Other examples may include the banking sector, automobile industries and beverages production industries etc. In telecommunication services, it is noted that once customers subscribe to a particular service provider, their long-term relations with that service provider have a great influence in the growth of the company among co-competitors. This is due to the fact that the mobile service providers offer same service leading to a high level of competition. As the market becomes more competitive, organizations tend to develop new marketing strategies in order to retain long-term relationships with their existing customers. Sarwat et al.(2013), suggest the basic rationale for brand switching include Price, Service Quality, Trust and Brand loyalty.

These rationales for brand switching serve as marketing strategies through which a particular mobile service provider influences their potential customers to either switch to their brand or remain loyal to the service provider.

Hidden Markov Model

The Hidden Markov Model (HMM) is descr- ibed as a doubly embedded stochastic process in which one of the stochastic processes is hidden but can be observed through the other stochastic process that emits the observation sequence. These stochastic processes are associated with a probability distribution. Rabiner (1989), gave a clear definition of the parameters of the HMM but in this paper, we defined these parameters as follows:

$\mathbf{N}=$ a finite set of $\mathrm{N}$-telecommunication networks;

$\mathrm{M}=\mathrm{a}$ finite set of $\mathrm{M}$-Rationale for brand switching;

\section{$P=\left\{P_{i j}\right\}$ is the transition probability of}

networks, where $\mathrm{P}_{\mathrm{ij}}$ is the probability of switching from one network $\mathrm{i}$ to another network j;

$B=b_{j}\left(O_{t}\right)$ is the probability of the rationale for brand switching, where $b_{j}\left(O_{t}\right)$ is the

probability of choosing a network $\mathrm{j}$ based on a rationale $\mathrm{O}$ at time $\mathrm{t}\left(\mathrm{i} . \mathrm{e} \mathrm{O}_{\mathrm{t}}\right.$ )

$\pi=\left\{\pi_{i}\right\}$ is the probability of current net-

work in use, where $p_{i}$ is the probability of starting with a particular network $\mathrm{i}$.

For simplicity, we denote the complete parameter of our model by $\lambda=(P, B, \pi)$.

\section{The decoding problem of HMM}

The distinction between the Markov model and the Hidden Markov model is the fact that the states in the Markov model (processes) are known to the observer, while the states in the HMM are considered hidden to the observer. In other words, given a sequence of observation, under the Markov Model we can depict with certainty the states that produced the observation sequence, while under the Hidden Markov Model one cannot uniquely depict the state that a given observation is emitted from, hence we 
say that the state sequence is hidden from the observer (Ibe, 2009).

The situation above is addressed as the decoding problem of HMM, which seeks to find the best (optimal) state sequence associated with a given observation sequence $\mathrm{O}$, of a given model $\lambda$. By optimal state sequence, we mean the state sequence that has the highest probability of producing the given observation sequence. To implement the solution of the decoding problem of HMM, Ibe (2009), defines the variable;

$\gamma_{t}(i)=P\left(q_{t}=s_{i} / O, \lambda\right)$

i.e., the probability of being in state $\mathrm{s}_{\mathrm{i}}$ at time $\mathrm{t}$, given the observation sequence $\mathrm{O}$, and the model $\lambda$. This can be expressed in terms of Forward-Backward variables as:

$\gamma_{t}(i)=\frac{\alpha_{t}(i) \beta_{t}(i)}{P(O / \lambda)}=\frac{\alpha_{t}(i) \beta_{t}(i)}{\sum_{i=1}^{N} \alpha_{t}(i) \beta_{t}(i)}$

Using equation (2), we can solve for the most likely state $\mathrm{q}_{\mathrm{t}}$ at time $\mathrm{t}$, as:

$$
q_{t}=\underset{1 \leq i \leq N}{\arg \max }\left[\gamma_{t}(i)\right] \quad 1 \leq \mathrm{t} \leq \mathrm{T}
$$

Equation (3), chooses the most likely state for each $t$, but the optimal state sequence in most cases may not be valid state sequence. Such situation results from the state transition of the model having a probability equal to zero. i.e.

$P_{i j}=0$ for some $\mathrm{i}$ and $\mathrm{j}$. An efficient method that best handles this situation is the Viterbi algorithm. This algorithm uncovers the hidden part of the HMM.

\section{Viterbi algorithm}

The viterbi algorithm as stated earlier, is used to find the most likely state sequence

$Q^{*}=\left\{q_{1}^{*}, q_{2}^{*}, \ldots, q_{T}^{*}\right\}$ for a given observa- tion sequence $O=\left\{O_{1}, O_{2}, \ldots, O_{T}\right\}$

The algorithm defines the variable as: $\quad \delta_{t}(i)$

$\delta_{t}(i)=\max _{1<i \leq N} P\left\{q_{1}, q_{2}, \ldots q_{t-1}, q_{t}=s_{i}, o_{1}, o_{2}, \ldots o_{t-1}, o_{t} / \lambda\right\}$

i.e, $\delta_{t}(i)$ is the largest probability along a single path that accounts for the first observations and ends in state $s_{\mathrm{i}}$. Another variable $\psi_{t}(j)$ stores the node of the incoming arc that leads to this most probable path. i.e.

$$
\psi_{t}(j)=\underset{1 \leq i \leq N}{\arg \max }\left\{\delta_{t-1}(i) P_{i j}\right\} . \text { The }
$$

The algorithm is given by:

Step 1: Initialization

$$
\delta_{1}(i)=\pi_{i} b_{i}\left(O_{1}\right) \quad 1 \leq \mathrm{i} \leq \mathrm{N}
$$

$\psi_{1}(i)=0$

Step 2: Recursion

$\delta_{t}(j)=\max _{1 \leq i \leq N}\left\{\delta_{t-1}(i) P_{i j}\right\} b_{j}\left(O_{t}\right) \quad 1 \leq \mathrm{i}, \mathrm{j} \leq \mathrm{N} ; 2 \leq \mathrm{t} \leq \mathrm{T}$

$$
\psi_{t}(j)=\underset{1 \leq i \leq N}{\arg \max }\left\{\delta_{t-1}(i) P_{i j}\right\}
$$

Step 3: Update time,

Set $\mathrm{t}=\mathrm{t}+1$ if $\mathrm{t}<\mathrm{T}$, go to step 2 otherwise go to step 4

Step 4: Termination

$$
\begin{gathered}
P^{*}=\max _{1 \leq i \leq N}\left\{\delta_{T}(i)\right\} \\
q_{T}^{*}=\underset{1 \leq i \leq N}{\arg \max }\left\{\delta_{T}(i)\right\}
\end{gathered}
$$

Step 5: Path (or state sequence) backtracking

$q_{t}^{*}=\psi_{t+1}\left(q_{t+1}^{*}\right) \quad \mathrm{t}=\mathrm{T}-1, \mathrm{~T}-2, \ldots, 1$ 
HMM-Based approach in brand switching...

29

The backtracking step allows the best state sequence to be found from the back pointers stored in the recursion step.

\section{Data collection}

The data was collated using the questionnaire that was administered to the 512 sampled respondents. The population of the University of Benin during the 2014/2015 academic session was 37,083 Persons. This population consists of 1,639 academic staff, 5,054 non-academic staff and 30,390 students. Employing the stratified random sampling with probability proportional to size, a sample of 23 academic staff, 70 nonacademic staff, and 419 students which gave a total sample size of 512 respondents was used for the analysis. The results are tabulated in Tables 1, 2 and 3 respectively.

Since the parameters of our model are probability measures, we consider the relative frequencies of the data obtained such that the relative frequencies in each row sum to 1 . The relative frequencies can thus be addressed as measures

Table1: Number of subscribers in each network

\begin{tabular}{ccccc}
\hline MTN & AIRTEL & GLOBACOM & ETISALAT & NITEL \\
\hline 134 & 127 & 122 & 101 & 28 \\
\hline
\end{tabular}

Table 2: Number of subscribers who choose a particular network based on a rationale

\begin{tabular}{lcccc}
\hline & PRICE & SERVICE QUALITY & TRUST & BRAND LOYALTY \\
\hline MTN & 48 & 33 & 36 & 17 \\
AIRTEL & 39 & 52 & 24 & 12 \\
GLOBACOM & 25 & 63 & 08 & 26 \\
ETISALAT & 37 & 32 & 21 & 11 \\
NITEL & 05 & 03 & 06 & 14 \\
\hline
\end{tabular}

Table 3: Number of subscribers who wish to switch from one network to another network

\begin{tabular}{cccccc}
\hline NETWORK & MTN & AIRTEL & GLOBACOM & ETISALAT & NITEL \\
\hline MTN & 52 & 38 & 32 & 12 & 00 \\
AIRTEL & 16 & 50 & 31 & 23 & 07 \\
GLOBACOM & 25 & 09 & 63 & 25 & 00 \\
ETISALAT & 20 & 19 & 22 & 32 & 08 \\
NITEL & 05 & 03 & 00 & 06 & 14 \\
\hline
\end{tabular}


of probabilities (i.e. $\sum_{j=1}^{n} P_{i j}=1$ ) which transform tables 1, 2, 3 to Tables 4, 5 and 6 .

In order to obtain an understanding of the underlying forces and structures that produced the observed data and then fit a model for predictions, we thus represent our situation expressed in Tables 4, 5 and 6 using the following model $\lambda=(P, B, \pi)$, and hence, generate a set of observable sequence $\mathrm{O}=\left[\mathrm{o}_{1}, \mathrm{O}_{2}, \ldots, \mathrm{O}_{\mathrm{T}}\right]$ to fit our model. Table 6 is represented in the state transition diagram given in Fig. 1.

\section{Making predictions with HMM}

The information gathered from the authors' data collection forms the parameters of their model. Thus given this model, the authors wish to observe five sets of strategies (Price, Service quality, Brand loyalty, Price, Trust) employable by the service providers in order to gain relevance and increase their long-term relationship with their service users. These observed strategies form the basis of authors' predictions. The question of interest is "As a service provider, if subscribers wish to switch from their current

Table 4: Probability of subscribers in each network

\begin{tabular}{lcccc}
\hline MTN & AIRTEL & GLOBACOM & ETISALAT & NITEL \\
\hline 0.2617 & 0.2480 & 0.2383 & 0.1973 & 0.0547 \\
\hline
\end{tabular}

Table 5: Probability of subscribers who choose a particular network based on a rationale

\begin{tabular}{lcccc}
\hline & PRICE & SERVICE QUALITY & TRUST & BRAND LOYALTY \\
\hline MTN & 0.3582 & 0.2463 & 0.2686 & 0.1269 \\
AIRTEL & 0.3071 & 0.4094 & 0.1890 & 0.0945 \\
GLOBACOM & 0.2049 & 0.5164 & 0.0656 & 0.2131 \\
ETISALAT & 0.3663 & 0.3168 & 0.2080 & 0.1089 \\
NITEL & 0.1786 & 0.1071 & 0.2143 & 0.5000 \\
\hline
\end{tabular}

Table 6: Probability of subscribers who wish to switch from one network to another network

\begin{tabular}{lccccc}
\hline & MTN & AIRTEL & GLOBACOM & ETISALAT & NITEL \\
\hline MTN & 0.3881 & 0.2836 & 0.2388 & 0.0895 & 0.0000 \\
AIRTEL & 0.1260 & 0.3937 & 0.2441 & 0.1811 & 0.0551 \\
GLOBACOM & 0.2049 & 0.0738 & 0.5164 & 0.2049 & 0.0000 \\
ETISALAT & 0.1980 & 0.1881 & 0.2179 & 0.3268 & 0.0792 \\
NITEL & 0.1786 & 0.1071 & 0.0000 & 0.2143 & 0.5000 \\
\hline
\end{tabular}


HMM-Based approach in brand switching... 31

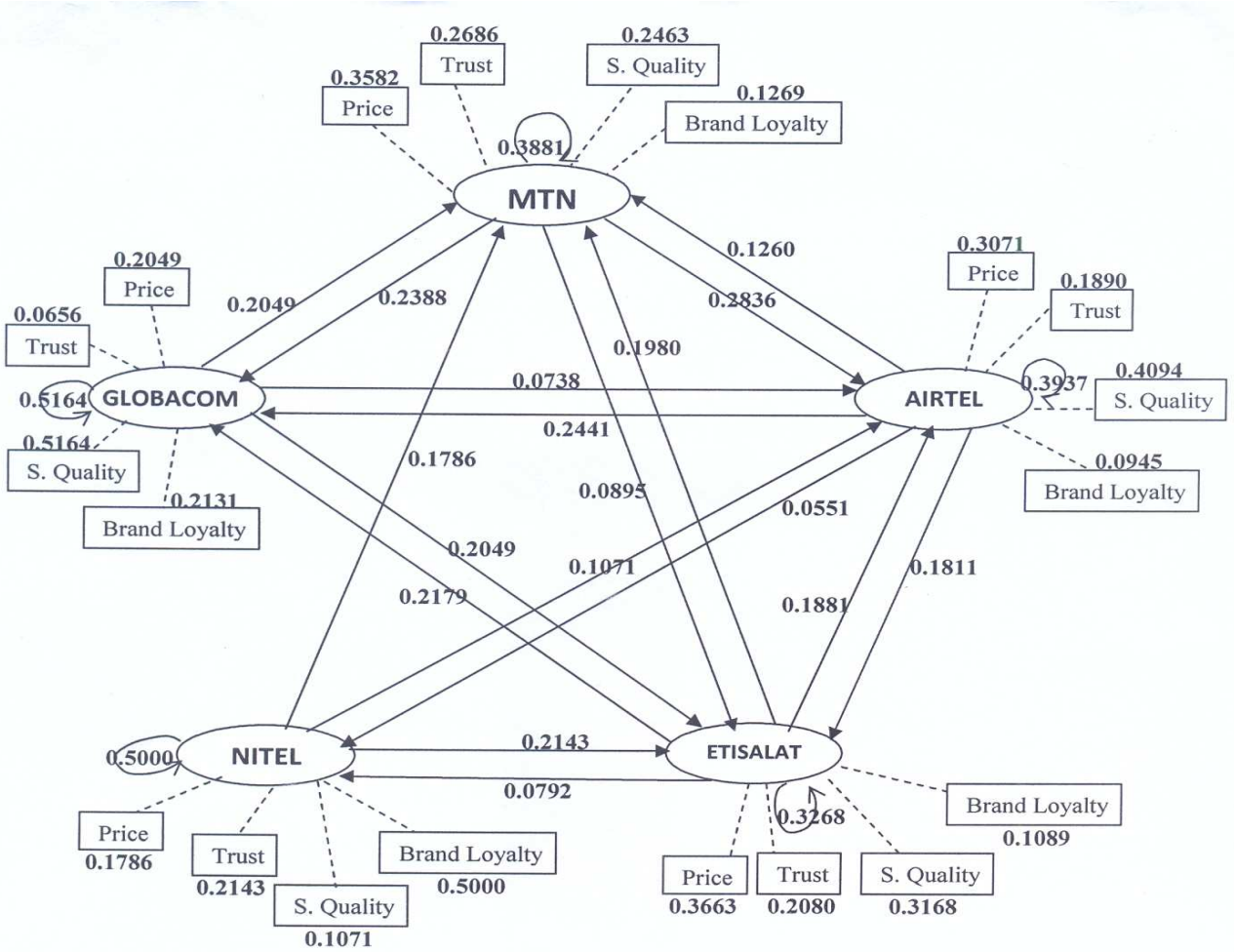

Fig. 1: Transition diagram of HMM showing the probability distribution of networks

network to another network based on these rationale (strategies) in a consecutive period of five years, which of the service providers will tend to gain more relevance in the telecommunication sector?" It is in this direction that the authors wish to address. In order to give an answer to this question, we make use of the Viterbi algorithm which tends to choose the most "reliable" network that produced the observable strategies, since the networks are hidden. Thus, given the model $\lambda=(\mathrm{P}, \mathrm{B}, \mathrm{p})$, and observable strategies (Price, Service Quality, Brand loyalty, Price, Trust), the result obtained using the algorithm stated in equations(5-10) which was implemented in R-software package is summarized in Table 7.
From the result in Table 7, the Viterbi algorithm at time $t=1$ considers the product of the probabilities of subscribers who started using a particular network based on the price factor. The system then updates to $t=2$ and considers the maximum probability of switching to a particular network from other networks. The process continues until $\mathrm{t}=5$.

Table 8 shows the argument $1 \leq i \geq N$ that corresponds with the maximum of the expression $\max _{1 \leq i \leq N}\left(\delta_{t-1}(i) p_{i j}\right)$ The last step of the Viterbi algorithm is the path (or state sequence) backtracking which is given by equation (10)

[ $\left.q_{t}{ }^{*}=\psi_{t+1}\left(q_{t+1}{ }^{*}\right)\right]$ as follows: 


$$
\begin{aligned}
& q_{5}^{*}=M \\
& q_{4}^{*}=\psi_{5}\left(q_{5}^{*}\right)=\psi_{5}(M)=M \\
& q_{3}^{*}=\psi_{4}\left(q_{4}^{*}\right)=\psi_{4}(M)=G \\
& q_{2}^{*}=\psi_{3}\left(q_{3}^{*}\right)=\psi_{3}(G)=G \\
& q_{1}^{*}=\psi_{2}\left(q_{2}^{*}\right)=\psi_{2}(G)=G
\end{aligned}
$$

Hence, the single best state sequence

$Q^{*}=\left\{q_{1}{ }^{*}, q_{2}{ }^{*}, q_{3}{ }^{*}, q_{4}{ }^{*}, q_{5}{ }^{*}\right\}$ that produced

the observable strategies (Price, Service Quality, Brand loyalty, Price, Trust) is given by \{GLOBACOM, GLOBACOM, GLOBACOM, MTN, MTN\}. and Trust] in a consecutive period of five years, the best marketing strategies for the mobile service provider [GLOBACOM] in the first three years are Price, Service Quality and Brand loyalty respectively. While the mobile service provider [MTN], should invest in the Pricing system and increase the level of Trust existing between them and their subscribers in the fourth and fifth year respectively. We observed from the result that there is a variation in the marketing strategy for each year. This implies that, in other to gain relevance in the telecommunication sector, mobile service providers should not be restricted to a particular marketing strategy but rather explore in diverse marketing strategies in the long run.

\section{REFERENCES}

Bhusari, V. and Patil, S. (2011). Application of Hidden Markov Model in Credit Card Fraud Detection. International Journal of Distri-

Table 8: Summary statistics of the result obtained using Viterbi algorithm (equations 7- 9)

\begin{tabular}{lccccc}
\hline NETWORKS & PRICE & $\begin{array}{l}\text { SERVICE } \\
\text { QUALITY }\end{array}$ & $\begin{array}{c}\text { BRAND } \\
\text { LOYALTY }\end{array}$ & PRICE & TRUST \\
\hline MTN & ----- & $\Psi_{2}(\mathrm{M})=\mathrm{M}$ & $\Psi_{3}(\mathrm{M})=\mathrm{M}$ & $\Psi_{4}(\mathrm{M})=\mathrm{G}$ & $\Psi_{5}(\mathrm{M})=\mathrm{M}$ \\
AIRTEL & ---- & $\Psi_{2}(\mathrm{~A})=\mathrm{A}$ & $\Psi_{3}(\mathrm{~A})=\mathrm{A}$ & $\Psi_{4}(\mathrm{~A})=\mathrm{A}$ & $\Psi_{5}(\mathrm{~A})=\mathrm{M}$ \\
GLOBACOM & ----- & $\Psi_{2}(\mathrm{G})=\mathrm{G}$ & $\Psi_{3}(\mathrm{G})=\mathrm{G}$ & $\Psi_{4}(\mathrm{G})=\mathrm{G}$ & $\Psi_{5}(\mathrm{G})=\mathrm{G}$ \\
ETISALAT & ----- & $\Psi_{2}(\mathrm{E})=\mathrm{E}$ & $\Psi_{3}(\mathrm{E})=\mathrm{G}$ & $\Psi_{4}(\mathrm{E})=\mathrm{G}$ & $\Psi_{5}(\mathrm{E})=\mathrm{E}$ \\
NITEL & ----- & $\Psi_{2}(\mathrm{~N})=\mathrm{N}$ & $\Psi_{3}(\mathrm{~N})=\mathrm{A}$ & $\Psi_{4}(\mathrm{~N})=\mathrm{G}$ & $\Psi_{5}(\mathrm{~N})=\mathrm{N}$ \\
\hline
\end{tabular}

\section{CONCLUSION}

The Hidden Markov model, when successfully applied, turns to be an efficient tool for modeling sequential data. In this work, we have been able to address a problem in brand switching using the Hidden Markov model. Our findings follow from the path backtracking step of the algorithm which suggests that, if subscribers of different networks decide to switch from their current network based on these rationales [Price, Service Quality, Brand loyalty, Price buted and Parallel Systems, 2(6): 202211

Bickel, P. J., Ritov, Y. and Ryden, T. (1998). Asymptotic Normality of the Maximum Likelihood Estimator for General Hidden Markov Models. The Annals of Statistics, 26(4): 1614-1635

Ezzaine, Z. (2006). Applications of artificial Intelligence in bioinformatics: A Review. 
HMM-Based approach in brand switching... 33

Expert Systems with Application, 30: 2-10

Gautam, P. and Chandhok, A. (2011). Switching Behaviour of Subscribers in Indian Telecom Sector. International Journal of Research in Finance and Marketing. 1(3):183191

Ghahramani, Z. (2001). An Introduction to Hidden Markov Models and Bayesian Networks. International Journal of Pattern Recognition and Artificial Intelligence. 15(1): 942.

Ibe, O. C. (2009). Markov Processes for Stochastic Modeling. Elsevier Academic Press.
U.S.A

Juang, B. H. and Rabiner, L. R. (1991). Hidden Markov Models for speech Recognition. Technometrics, 33(3): 251-272

Rabiner, L. R. (1989). A Tutorial on Hidden Markov Models and Selected Applications in Speech Recognition. Proceedings of IEEE, 77(2): 257-286

Sarwat, A., Chandio, A. K., Shaikh, S., Bhand, M., Ghumro, B. A. and Khuhro, A. K. (2013). Factors Behind Brand Switching in Cellular Networks. International Journal of Asian Social Science, 3(2):299-307 